\title{
Titration Error in Polyprotic Acid-Base Titrations: Applications to Titration of Vinegar, Cola Drinks and Antibiotic Batches
}

\author{
Julia Martín, Gloria Cañamares Marin, Agustin G. Asuero* \\ Department of Analytical Chemistry, The University of Seville, Spain
}

*Corresponding Author: Agustin G. Asuero, Department of Analytical Chemistry, The University of Seville, Spain

\begin{abstract}
Though a number of excellent papers have been published dealing with titration error in acid-base chemical systems of the monoprotolytic kind, the estimation of titration error of polyprotic acid (or polyacid bases and ampholytes) have received a scarce attention. Nevertheless, using the dissociation and formation (n) functions the chemical complexity involved in such kind of calculations is reduced considerably. Simple general expressions, based on the inverse approach for titration curves, i.e., $V=f(p H)$, are derived for titration error of polyprotic acid $\left(H_{N} A\right)$, polyprotic bases $\left(B\right.$ or $\left.N a_{N} T\right)$ or ampholytes $\left(N a_{N-x} H_{x} T\right)$, in the nthequivalence point (1 to $N$ for polyprotic acid or base, and 1 to $x$ (or $N$-x) for ampholyte titrated with strong base (strong acid)). Among possible analytical applications the determination of acetic acid in vinegar, phosphoric acid in Coca-Cola, and vancomycin purity in batches of raw material were selected for study.
\end{abstract}

Keywords: Titration error; Polyprotic acids and bases;Potentiometric titration; Vinegar; Coca-Cola; Vancomycin

\section{INTRODUCTION}

The speciation of polyprotic acids [1-3] is a common problem in analytical, pharmaceutical and food chemistry, covering applications from $\mathrm{pH}$ control in simple and complex experiments [4], to the evaluation of acidity constants [5] of polyprotic systems (polyprotic acids, polyacid bases, or ampholytes). Titration curves and titration error of such complex systems are readily derived by the incorporation of the molar fractions of the dissociated species and the formation function, $\tilde{n}$ (Bjerrum index or average number of bound protons) into the equations defining the mass and charge balances. Working in a medium of ionic strength fixed considerably reduces the mathematical complexity.

Although a number of excellent studies corresponding to the titration error of single equilibria have been published [6], the estimation of the polyprotic acid titration error has received scarce attention. Various systems of analytical interest, including monoprotic and diprotic acids and bases, triprotic and tetraprotic acids, and ampholytes; i.e. acetic acid (vinegar), phosphoric acid (Coca Cola), and vancomycin (antibiotic, antibacterial), are subject of consideration in this paper.

\section{EVALUATION CURVE OF A POLYPROTIC ACID}

The calculation of $\mathrm{pH}$ as a function of the volume $\mathrm{V}$ of titrant generally requires the solution of a high degree equation [7-8]. The usual approach is to write a polynomial equation in terms of hydrogen ion concentration and then find a positive root, which is a complex task (unless approximations are introduced), requiring the use of a computer. The inverse approach [10-11] for the derivation of the titration curves involves calculating the volume of titrant $\mathrm{V}$ (dependent variable, extensive), added to a given volume of acid (or acids) as a function of $\mathrm{pH}$ (independent variable, intensive). It is very easy to obtain and it does not require any of the simplifications generally performed in textbooks.

In the potentiometric titration of a neutral polyprotic acid $\mathrm{H}_{\mathrm{N}} \mathrm{A}$ [10], to a volume $\mathrm{V}_{0}$ of initial acid (which may contain the background electrolyte) at an initial concentration $\mathrm{C}_{\mathrm{A}}$, is added a volume $\mathrm{V}$ of strong titrant base (which may contain the background electrolyte at the same concentration as the acid solution), $\mathrm{BOH}$, at a concentration $\mathrm{C}_{\mathrm{B}}$. Electroneutrality rule is satisfied at any moment in the course of the titration (charges are omitted in the following for simplicity).

$[H]+[B]=[O H]+\left[H_{N-1} A\right]+2\left[H_{N-2} A\right]+\ldots+(N-1)[H A]+N[A]$ 
Given the increase in volume of the solution in the course of titration we get the mass balances

$C_{A} \frac{V_{0}}{V_{0}+V}=\left[H_{N} A\right]+\left[H_{N-1} A\right]+\left[H_{N-2} A\right]+\ldots+[H A]+[A]=\sum_{0}^{N}\left[H_{j} A\right]$

$C_{B} \frac{V}{V_{0}+V}=[B]$

Taking into account that $f_{j}$ is the fraction molar of the species $\mathrm{H}_{\mathrm{j}} \mathrm{A}^{(\mathrm{N}-\mathrm{j})}$

$f_{j}=\frac{\left[H_{j} A\right]}{\sum\left[H_{j} A\right]}$

we have

$$
\begin{aligned}
& {\left[H_{j} A\right]=f_{j} \sum\left[H_{j} A\right]=f_{j} C_{A} \frac{V_{0}}{V_{0}+V}} \\
& \sum j\left[H_{j} A\right]=C_{A} \frac{V_{0}}{V_{0}+V} \sum j f_{j}=C_{A} \frac{V_{0}}{V_{0}+V} \tilde{n}
\end{aligned}
$$

Where $\tilde{n}$ is the formation function [11] or Bjerrum index

$$
\begin{aligned}
\tilde{n}= & \frac{C_{H}-[H]}{C_{A} \frac{V_{0}}{V_{0}+V}}=\frac{[H A]+2\left[H_{2} A\right]+\ldots+N\left[H_{N} A\right]}{[A]+[H A]+\left[H_{2} A\right]+\ldots+\left[H_{N} A\right]}= \\
= & \frac{j \beta_{j}[H]^{j}}{\sum_{0}^{N} \beta_{j}[H]^{j}}=\frac{\sum_{0}^{N} j\left[H_{j} A\right]}{\sum_{0}^{N}\left[H_{j} A\right]}=f_{1}+2 f_{2}+\ldots+N f_{N}=\sum_{0}^{N} j f_{j}
\end{aligned}
$$

Being $\beta_{j}$ the global stability constant related with the formation constants $K_{j}^{\prime} \mathrm{s}$ and the acidity constants $K_{a}$ 's by means of

$\beta_{j}=\frac{\left[H_{j} A\right]}{[H]^{j}[A]}=K_{1} K_{2} \ldots K_{j}=\frac{1}{K_{a N}} \frac{1}{K_{a, N-1}} \ldots \frac{1}{K_{a, N+1-j}}$

corresponding to the formation global equilibrium $A+j H=H_{\mathrm{j}} A, \mathrm{~K}_{\mathrm{j}}$ is the formation constant corresponding to the equilibrium $A_{\mathrm{j}-1} H+H=A_{\mathrm{j}} H$, y $K_{\mathrm{aj}}$ the acidity constant corresponding to the equilibrium $H_{\mathrm{N}+1-\mathrm{j}} A=H_{\mathrm{N}-\mathrm{j}} A+H$

$$
\begin{gathered}
K_{a j}=\frac{\beta_{N-j}}{\beta_{N+1-j}}=\frac{1}{K_{j}} \\
f_{j}=\frac{\beta_{j}[H]^{j}}{\sum_{0}^{N} \beta_{j}[H]^{j}}
\end{gathered}
$$

By combining Eqns. (2)-(6) we get

$$
\begin{aligned}
\Delta & =[H]-[O H]= \\
& =\left(f_{N-1}+2 f_{N-2}+\ldots+(N-1) f_{1}+N f_{0}\right) C_{A} \frac{V_{0}}{V_{0}+V}-C_{B} \frac{V}{V_{0}+V} \\
\Delta & =\frac{(N-\tilde{n}) C_{A} V_{0}-C_{B} V}{V_{0}+V}
\end{aligned}
$$

and on rearrangement 
$V=V_{0} \frac{(N-\tilde{n}) C_{A}-\Delta}{C_{B}+\Delta}$

which allow to evaluate the secondary variable $\tilde{\mathrm{n}}$ as a function of titration parameters

$\tilde{n}=N-\frac{C_{B} V}{C_{A} V_{0}}-\frac{\Delta}{C_{A} \frac{V_{0}}{V_{0}+V}}=N-T-\frac{\Delta}{C_{A} \frac{V_{0}}{V_{0}+V}}$

where $\mathrm{T}$ is the titrated fraction.

\section{TITRATION ERROR IN POLYPROTIC ACID-BASE TITRATIONS: THEORY}

From the mass and charge balances, it may easily be shown [7-8] that the fraction of acid titrated in the titration of a volume $\mathrm{V}_{0}$ of a neutral polyprotic acid, $\mathrm{H}_{\mathrm{N}} \mathrm{A}$, of concentration $\mathrm{C}_{\mathrm{A}}$ with a volume $\mathrm{V}$ of strong base e.g. $\mathrm{BOH}$, of concentration $\mathrm{C}_{\mathrm{B}}$ is related to the formation function $\tilde{\mathrm{n}}$ by means of (ionic strength is assumed to be constant)

$T=\frac{C_{B} V}{C_{A} V_{0}}=\frac{[O H]-[H]}{C_{A} \frac{V_{0}}{V_{0}+V}}+N-\tilde{n}$

Then the (fractional) titration error at then-th end point will be given by

$\Delta T=\left[\frac{T-n}{n}\right]_{\text {end }}=\frac{1}{n}\left[\frac{[O H]-[H]}{C_{A}}+N-\tilde{n}-n\right]_{\text {end }}$

The volume (dilution) factor near the $n$-th equivalence point, can be approximated by using $\mathrm{T}=\mathrm{n}$ to be

$C_{A, \text { end }}=C_{A} \frac{V_{0}}{V_{0}+V_{\text {end }}}=\frac{C_{A}}{1+r T_{\text {end }}}=\frac{C_{A}}{1+r n}$

where dilution coefficient $r$ is given by

$r=\frac{C_{A}}{C_{B}}$

It is to be noted that it is not necessary to know the values of $\mathrm{pH}$ at equivalence points in order to calculate the error.

Note in Eqn. (15) the sum of two terms; one that manifests itself at low or high $\mathrm{pH}$ values, which is dependent on the concentration $\mathrm{C}_{\mathrm{A}}$, and another, $N-\tilde{n}-n$, which is independent of the concentration (N$\tilde{n}$ is the degree of deprotonation of the acid).

\subsection{Application to Diprotic Acid}

In the case of a diprotic acid, $N=2, \tilde{n}=f_{1}+2 f_{2}$ and when $n=1$ the Eqn. (15) becomes

$$
\begin{aligned}
& \Delta T=\frac{[\mathrm{OH}]-[H]}{C_{A, \text { end }}}+2-\left(f_{1}+2 f_{2}\right)-1=\frac{[\mathrm{OH}]-[H]}{C_{A, \text { end }}}+1-f_{1}-2 f_{2}= \\
& \frac{[\mathrm{OH}]-[H]}{C_{A, \text { end }}}+\left(f_{0}+f_{1}+f_{2}\right)-f_{1}-2 f_{2}=\frac{[\mathrm{OH}]-[H]}{C_{A, \text { end }}}+f_{0}-f_{2}
\end{aligned}
$$

since the sum of the molar fractions of the different species of diprotic acid is equal to unity, $\mathrm{f}_{0}+\mathrm{f}_{1}+\mathrm{f}_{2}=1$. The Eqn. (18) corresponds to Eqn. (16) of the paper of Butcher and Fernando [12], since for the diprotic acid

$$
f_{0}=\frac{1}{1+\beta_{1}[H]+\beta_{2}[H]^{2}}=\frac{1}{1+\frac{[H]}{K_{a 2}}+\frac{[H]^{2}}{K_{a 2} K_{a 1}}}=\frac{K_{a 1} K_{a 2}}{[H]^{2}+K_{a 1}[H]+K_{a 1} K_{a 2}}
$$




$$
f_{2}=\frac{\beta_{2}[H]^{2}}{1+\beta_{1}[H]+\beta_{2}[H]^{2}}=\frac{\frac{[H]^{2}}{K_{a 1} K_{a 2}}}{1+\frac{[H]}{K_{a 2}}+\frac{[H]^{2}}{K_{a 2} K_{a 1}}}=\frac{[H]^{2}}{[H]^{2}+K_{a 1}[H]+K_{a 1} K_{a 2}}
$$

where the global stability constants, successive formation constants and acid dissociation constants of the diprotic acid are related through the expressions

$\beta_{1}=K_{1}=\frac{1}{K_{a 2}}$

$\beta_{2}=K_{1} K_{2}=\frac{1}{K_{a 2}} \cdot \frac{1}{K_{a 1}}$

When we titrate to the second equivalence point, $\mathrm{n}=2$, the Eqn. (15) leads to

$$
\begin{aligned}
\Delta T= & \frac{1}{2}\left[\frac{[O H]-[H]}{C_{A, \text { end }}}+2-\left(f_{1}+2 f_{2}\right)-2\right]=\frac{1}{2}\left[\frac{[O H]-[H]}{C_{A, \text { end }}}-f_{1}-2 f_{2}\right]= \\
& \frac{[O H]-[H]}{2 C_{A, \text { end }}}-\frac{f_{1}}{2}-f_{2}
\end{aligned}
$$

with

$$
f_{1}=\frac{\beta_{1}[H]}{1+\beta_{1}[H]+\beta_{2}[H]^{2}}=\frac{\frac{[H]}{K_{a 2}}}{1+\frac{[H]}{K_{a 2}}+\frac{[H]^{2}}{K_{a 2} K_{a 1}}}=\frac{K_{a 1}[H]}{[H]^{2}+K_{a 1}[H]+K_{a 1} K_{a 2}}
$$

The Eqn. (23) corresponds to Eqn. (18) of the paper of Butcher and Fernando [12].

\subsection{Application to Monoprotic Acid}

For a weak monoprotic acid, $\mathrm{N}=1, \tilde{\mathrm{n}}=\mathrm{f}_{1}$, and Eqn. (15) becomes

$$
\Delta T=\frac{[\mathrm{OH}]-[\mathrm{H}]}{C_{A, \text { end }}}+1-f_{1}-1=\frac{[\mathrm{OH}]-[\mathrm{H}]}{C_{A, \text { end }}}-f_{1}
$$

being $\mathrm{f}_{1}$ in this case equal to

$$
f_{1}=\frac{\beta_{1}[H]}{1+\beta_{1}[H]}=\frac{\frac{[H]}{K_{a}}}{1+\frac{[H]}{K_{a}}}=\frac{[H]}{[H]+K_{a}}=\frac{1}{1+\frac{K_{a}}{[H]}}
$$

The Eqn. (25) corresponds to Eqn. (7) of the paper of Butcher y Fernando [12] already quoted. For a strong acid, $\mathrm{f}_{1}=0$, and the titration error is given by the first part of the second member of Eqn. (25): $\Delta \mathrm{T}=\left(\left[\mathrm{OH}^{-}\right]-\left[\mathrm{H}^{+}\right]\right) / \mathrm{C}_{\mathrm{A}, \text { end }}$.

\subsection{Hyperbolic Sine Expression for Titration Error: Polyprotic Acid}

The Eqn. (15) can be transformed into a hyperbolic sine relationship, as we will see in the following. The difference $[\mathrm{OH}]-[\mathrm{H}]$ can be expressed as

$$
[\mathrm{OH}]-[H]=\frac{K_{w}^{c}}{[H]}-[H]=\sqrt{K_{w}^{c}}\left(\frac{\sqrt{K_{w}^{c}}}{[H]}-\frac{[H]}{\sqrt{K_{w}^{c}}}\right)
$$

and taking into account the definition of hyperbolic sine 
$\sinh x=\frac{e^{x}-e^{-x}}{2}$

we get

$\Delta T=\frac{1}{n}\left[\frac{2 \sqrt{K_{w}^{c}}}{C_{A}} \sinh \left(1 n 10\left(p[H]-\frac{p K_{w}^{c}}{2}\right)\right)+N-\tilde{n}-n\right]$

\section{TITRATION CURVE OF POLYACID BASES AND AMPHOLYTES}

A volume $\mathrm{V}_{0} \mathrm{~mL}$ of a polyacid base $\mathrm{Na}_{\mathrm{N}} \mathrm{A}$ of concentration $\mathrm{C}_{\mathrm{B}}$, may be titrated with a volume $\mathrm{V}$ of strong monobasic acid $\mathrm{HX}$ of concentration $\mathrm{C}_{\mathrm{A}}$, to give $\mathrm{HA}, \mathrm{H}_{2} \mathrm{~A} \ldots \mathrm{H}_{\mathrm{N}} \mathrm{A}$. We also may titrate a neutral polyacid base $\mathrm{B}$ which undergoes, when titrated with the strong acid, $\mathrm{N}$ successive protonations to give $\mathrm{BH}^{+}$, $\mathrm{BH}_{2}{ }^{2+}, \ldots \mathrm{BH}_{\mathrm{N}}{ }^{\mathrm{N}+}$.

An ampholyte $\mathrm{Na}_{\mathrm{N}-\mathrm{x}} \mathrm{H}_{\mathrm{x}} \mathrm{T}$ may be titrated either with a monoprotic strong base or a strong acid, respectively. Note that the charge which supports $\mathrm{T}$ is $-\mathrm{N}$, and that for $\mathrm{x}=\mathrm{N}$ coincides with the neutral polyprotic acid $\mathrm{H}_{\mathrm{N}} \mathrm{T}$, and for $\mathrm{x}=0$ we get the $\mathrm{N}$-charged polyacid base situation, $\mathrm{Na}_{\mathrm{N}} \mathrm{T}$. A volume $\mathrm{V}_{0} \mathrm{~mL}$ of the $\mathrm{Na}_{\mathrm{N}-\mathrm{x}} \mathrm{H}_{\mathrm{x}}$ Tampholyte of concentration $\mathrm{C}_{\mathrm{A}}$, may be titrated by adding $\mathrm{V} \mathrm{mL}$ of a strong base, i.e. $\mathrm{KOH}$, of concentration $\mathrm{C}_{\mathrm{B}}$. For the reverse titration, $\mathrm{V}_{0} \mathrm{~mL}$ of $\mathrm{Na}_{\mathrm{N}-\mathrm{x}} \mathrm{H}_{\mathrm{x}}$ Tampholyte of concentration $\mathrm{C}_{\mathrm{B}}$, is titrated with a volume $\mathrm{V}$ of strong monoprotic acid, i.e., hydrochloric acid. From the mass and charge balances (as for the case of polyprotic acid) we get the results compiled in Table 1, where the expression for the titration curve, the titration error formula as well as an alternative titrated fraction expression are shown. Expressions of the titration errors for particular cases are easily deduced from the general expression contained in Table 1, as we have previously seen for the polyprotic acid case.

Table 1. Titration curve, titration error and titration fraction expressions.

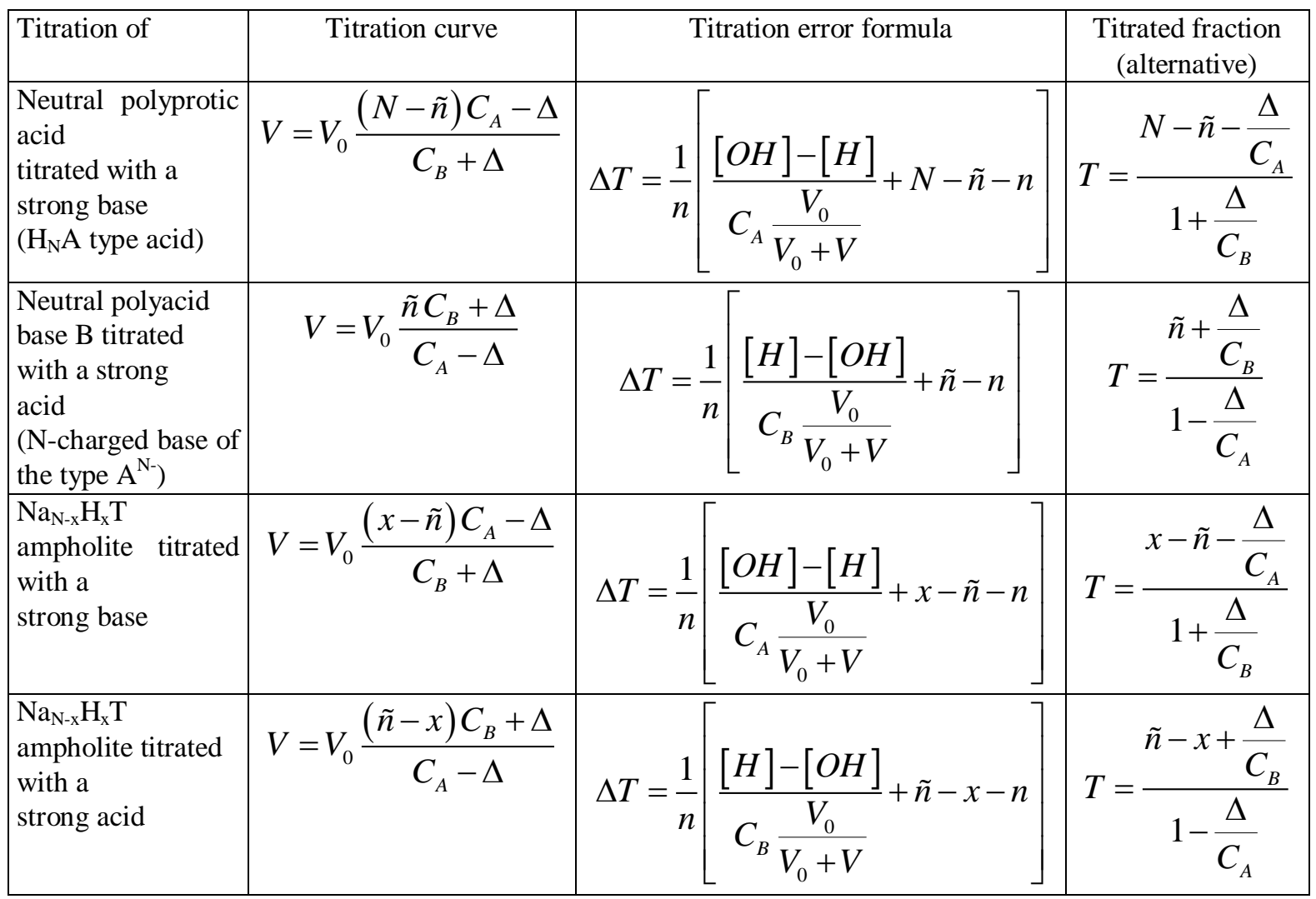

\section{TITRATION ERROR OF ACETIC ACID AND IST DETERMINATION IN VINEGAR}

The data corresponding to a titration of $\mathrm{HCH}_{3} \mathrm{COO}$ (plus $\mathrm{HCl}$ ) using a Metrohm 702 Titrino automatic titrator [13] coupled with a combined $\mathrm{pH}$ electrode with $\mathrm{NaOH}$ are shown in Table 2, and Figure 1 with the derivative curve obtained incrementally. 
Titration Error in Polyprotic Acid-Base Titrations: Applications to Titration of Vinegar, Cola Drinks and Antibiotic Batches

Table 2. Titration with $\mathrm{NaOH} 0.4905 \mathrm{M}$, of 3.96 mmol of acetic acid plus 0.484 mmol de HCl dissolved in 200 $m L$ of $\mathrm{KCl} 0.10 \mathrm{M}$.

\begin{tabular}{|c|c|c|c|c|c|c|c|c|c|c|c|}
\hline $\mathrm{V}(\mathrm{mL})$ & $\mathrm{pH}$ & $\mathrm{V}(\mathrm{mL})$ & $\mathrm{pH}$ & $\mathrm{V}(\mathrm{mL})$ & $\mathrm{pH}$ & $\mathrm{V}(\mathrm{mL})$ & $\mathrm{pH}$ & $\mathrm{V}(\mathrm{mL})$ & $\mathrm{pH}$ & $\mathrm{V}(\mathrm{mL})$ & $\mathrm{pH}$ \\
\hline 0.00 & 2.79 & 1.80 & 3.87 & 3.60 & 4.50 & 5.40 & 4.92 & 7.20 & 5.38 & 9.00 & 7.23 \\
\hline 0.30 & 2.89 & 2.10 & 4.01 & 3.90 & 4.58 & 5.70 & 4.98 & 7.50 & 5.49 & 9.30 & 10.14 \\
\hline 0.60 & 3.06 & 2.40 & 4.15 & 4.20 & 4.67 & 6.00 & 5.05 & 7.80 & 5.61 & 9.60 & 10.85 \\
\hline 0.90 & 3.26 & 2.70 & 4.25 & 4.50 & 4.72 & 6.30 & 5.12 & 8.10 & 5.76 & 9.90 & 11.20 \\
\hline 1.20 & 3.48 & 3.00 & 4.35 & 4.80 & 4.78 & 6.60 & 5.21 & 8.40 & 5.97 & 10.20 & 11.39 \\
\hline 1.50 & 3.72 & 3.30 & 4.42 & 5.10 & 4.85 & 6.90 & 5.29 & 8.70 & 6.28 & 10.50 & 11.54 \\
\hline
\end{tabular}

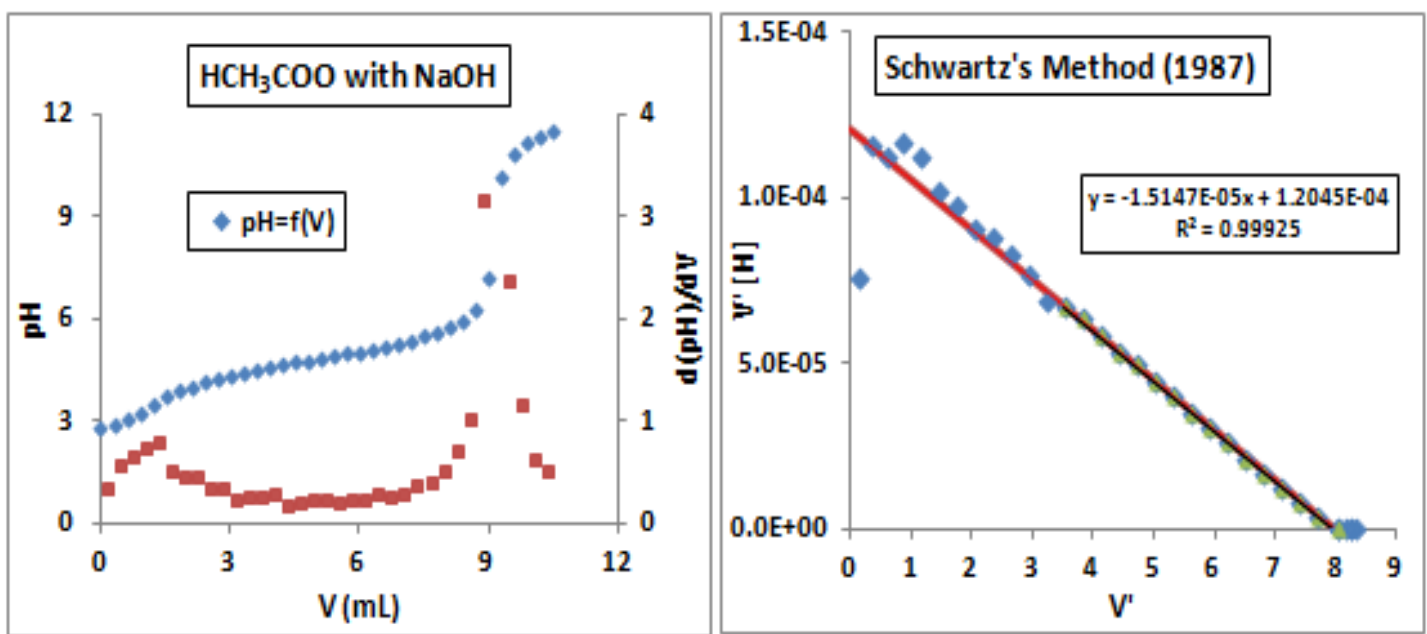

Figure 1. Left: Titration of $\mathrm{NaOH} 0.4905 \mathrm{M}$ of $200 \mathrm{~mL}$ de $\mathrm{HCH}_{3} \mathrm{COO} 0.0198 \mathrm{M}+\mathrm{HCl} 0.00242 \mathrm{M}$ and derivative curve. Right: Schwartz' method. pH-meter calibrated with buffers of pH 4.00, 7.00 and 9.00.

The theoretical volume required reaching the $2^{\text {nd }}$ equivalence point is $0.987+8.073=9.060 \mathrm{~mL}$. The derivative curve shows a maximum at $8.85 \mathrm{~mL}$ (minimum at 9.15 on the $\mathrm{dV} / \mathrm{dpH}$ curve versus $\mathrm{V}$ ), so the valuation error will be

$E=T-1=\frac{C_{B} V-C_{H} V_{0}}{C_{A} V_{0}}-1=\frac{C_{B} V_{p f 2}}{C_{B} V_{p e 2}}-1=\frac{V_{p f 2}}{V_{p e 2}}-1=\frac{8.85-0.987}{8.073}-1=-0.026$

Taking $9.15 \mathrm{~mL}$ the error is 0.011 . On the other hand, from Eqn. (12) taking into account the two acids, removing denominators and regrouping terms is reached to the expression

$\frac{\Delta\left(V_{0}+V\right)}{C_{B}}+V-V_{e q 1}=V^{\prime}=V_{e q 2} f_{0.2}=V_{e q 2} \frac{K_{a}}{K_{a}+\left[H^{+}\right]}$

which is of the form (Schwartz, 1987)

$V\left[H^{+}\right]=K_{a} V_{e q 2}-K_{a} V^{\prime}$

from which the values of 7.952, $4.82(\mathrm{I}=0.1)$ and 0.0195 for $\mathrm{V}_{\mathrm{eq} 2}, \mathrm{pK}_{\mathrm{a}}$ and $\mathrm{C}_{\mathrm{A}}$, respectively, are obtained. Assuming the values of the starting parameters as absolute, the error is given by: $\mathrm{E}=(7.952$ / 8.073) $-1=-0.015$ or $-1.5 \%$. Kraft [13] obtains a $\mathrm{pK}_{\mathrm{a}}$ of 4.83 for that data series, using a different method.

The calculation of the titration error is a common analytical problem. Given the acidity constants, the error associated with the $\mathrm{pH}$ range of colour change is estimated. The $\mathrm{pH}$ limits of these ranges are tabulated [14-15] and only need to calculate the corresponding titration volumes. The calculation is therefore simple: the extreme $\mathrm{pH}$ 's of the indicator range are selected and $\mathrm{T}\left(=\mathrm{V} / \mathrm{V}_{\mathrm{eq}}\right)$ is calculated for these limits (Table 3), determining the resulting error $\Delta \mathrm{T}\left(=\left(\mathrm{V} / \mathrm{V}_{\mathrm{eq}}\right)-1\right)$. Likewise, the titration error resulting from a preset value or from a $\mathrm{pH}$ reading can be obtained immediately. 
Titration Error in Polyprotic Acid-Base Titrations: Applications to Titration of Vinegar, Cola Drinks and Antibiotic Batches

Table 3. Estimation of the titration error corresponding to the transition $p H$ ranges of the indicator used in the titration of $50 \mathrm{~mL}$ of acetic acid $\left(p K_{a}=4.76\right)$ with sodium hydroxide at the indicated concentrations $\left(p K_{w}=\right.$ 14.00).

\begin{tabular}{|c|c|c|c|c|c|c|}
\hline $\mathrm{HCH}_{3} \mathrm{COO}$ & $\mathrm{C}_{\mathrm{A}}(\mathrm{M})$ & 0.0833 & 0.00833 & 0.000833 & 0.000833 & 0.000833 \\
\hline $\mathrm{NaOH}$ & $\mathrm{C}_{\mathrm{B}}(\mathrm{M})$ & 0.0833 & 0.00833 & 0.000833 & 0.001666 & 0.004165 \\
\hline Indicator & pH Range & \multicolumn{5}{|c|}{$\begin{array}{l}\text { Error percentage of titration corresponding to the extreme values of the } \mathrm{pH} \text { range of the } \\
\text { tabulated indicators }(\% \Delta \mathrm{T})\end{array}$} \\
\hline Phenol Red & $6.4-8.0$ & $-2.24--0.06$ & $-2.25--0.03$ & $-2.33-0.18$ & $-2.31-0.12$ & $-2.29-0.09$ \\
\hline Neutral Red & $6.8-8.0$ & $-0.90--0.06$ & $-0.91--0.03$ & $-0.93-0.18$ & $-0.92-0.12$ & $-0.92-0.09$ \\
\hline Cresol Red & $7.2-8.8$ & $-0.36-0.01$ & $-0.36-0.14$ & $-0.34-1.52$ & $-0.34-1.13$ & $-0.35-0.90$ \\
\hline$\alpha$-Naphtholphthalein & $7.3-8.7$ & $-0.29-0.00$ & $-0.28-0.11$ & $-0.25-1.20$ & $-0.26-0.89$ & $-0.27-0.71$ \\
\hline Cresol Purple & $7.4-9.0$ & $-0.23-0.02$ & $-0.22-0.23$ & $-0.18-2.42$ & $-0.19-1.81$ & $-0.20-1.44$ \\
\hline Thymol Blue & $8.0-9.6$ & $-0.06-0.09$ & $-0.03-0.96$ & $0.18-10.04$ & $0.12-7.34$ & $0.09-5.79$ \\
\hline Phenolphthalein & $8.2-10.0$ & $-0.03-0.24$ & $0.00-2.43$ & $0.34-27.28$ & $0.25-19.16$ & $0.19-14.76$ \\
\hline
\end{tabular}

Acetic acid is a component of vinegar, a water-miscible sour-tasting liquid, derived from the acetic fermentation of alcohol assisted by bacteria Mycodermaaceti. The concentration of vinegar in acetic acid is about 5\%; ie, $0.833 \mathrm{M}$. Titration curves corresponding to 1:10, 1:100 and 1:1000 dilutions are shown in the top left-hand side of Fig. 2. Titration error (in the interval of $-1 \%$ to $1 \%$ ) for the different molar concentrations of acid is drawn in Fig. 2 middle. The $\mathrm{pH}$ at the equivalence point (Fig. 2 bottom) fluctuates between 7.699 and 7.806 when a $0.000833 \mathrm{M}$ acid is titrated with a strong base solution 1, 2, 3, 4 and 5 times more concentrated. The calculations made allow us to verify (Table 3) that neutral red, cresol red and $\alpha$-naphtholphthalein are satisfactory indicators for the titration of acetic acid in all cases. Thymol blue and phenolphthalein are not recommended except at high concentrations of acid. Natural vinegars also contain small amounts of tartaric acid and citric acid. Among the varieties of vinegar are wine, aceto-balsamic, Sherry, cider or apple, and Porto. The concentration of acetic acid in vinegar ranges from $3 \%$ to $5 \%$.

It is also possible to titrate vinegar solution up to a fixed endpoint, in order to avoid the plotting of the entire potentiometric titration curve. This makes it necessary to know how the titration error varies with the acid concentration at given $\mathrm{pH}$ values (Fig. 3). For example, for a 1:250 dilution of vinegar, its $\mathrm{pC}_{\mathrm{A}}$ will be of the order of 2.50 , with titration errors lower than $1 \%$ if the titration is carried out to a $\mathrm{pH}$ of 7.2 to 9.2. If higher accuracy is desired, the above $\mathrm{pH}$ range should be limited, using the same diagram. Bottles of vinegar of different format are shown in Fig. 4. The experimental titration curve of a dark mahogany coloured Sherry vinegar (Fig. 5), shows that at pH 7.4-9.1 the error is minimal, according to the developed theory. The degree of acidity of the Sherry vinegar tested is $7.51 \%$, higher than that of conventional vinegar, whose acidity degree was equal to $6.98 \%$. In both cases we get higher values than those declared in label values ( 7 and $6 \%$, respectively). The $\mathrm{pH}$ value at $\mathrm{T}=0.5$ is 4.53.
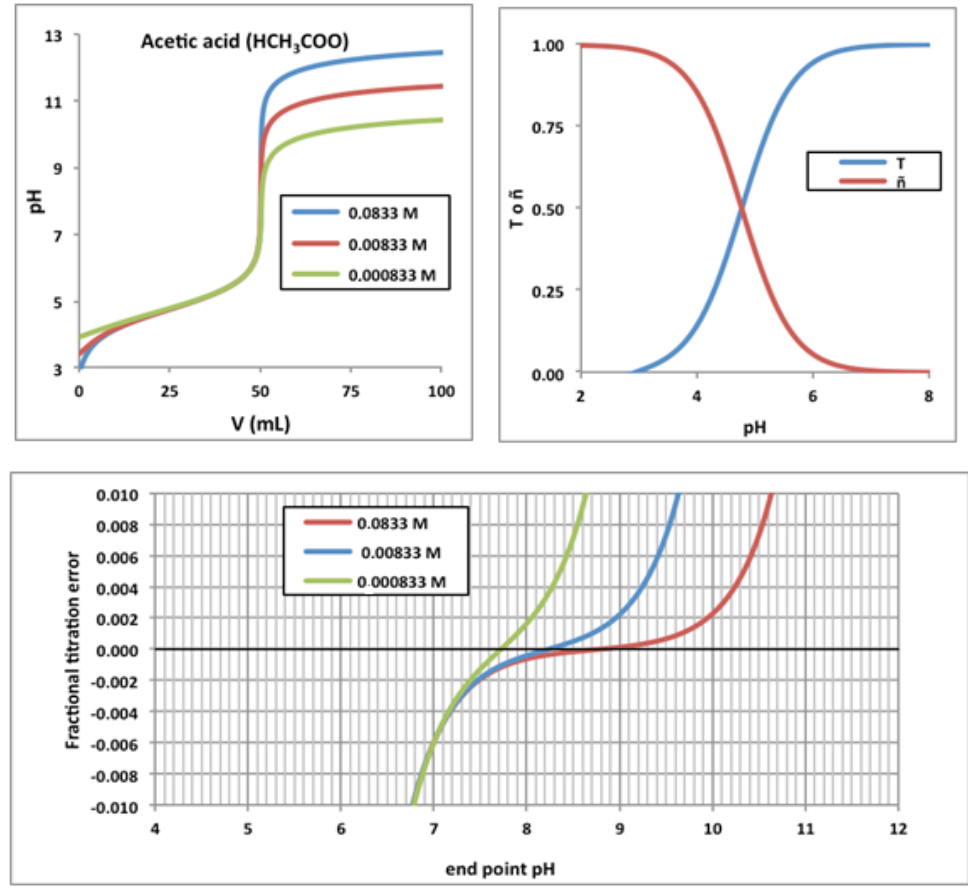
Titration Error in Polyprotic Acid-Base Titrations: Applications to Titration of Vinegar, Cola Drinks and Antibiotic Batches

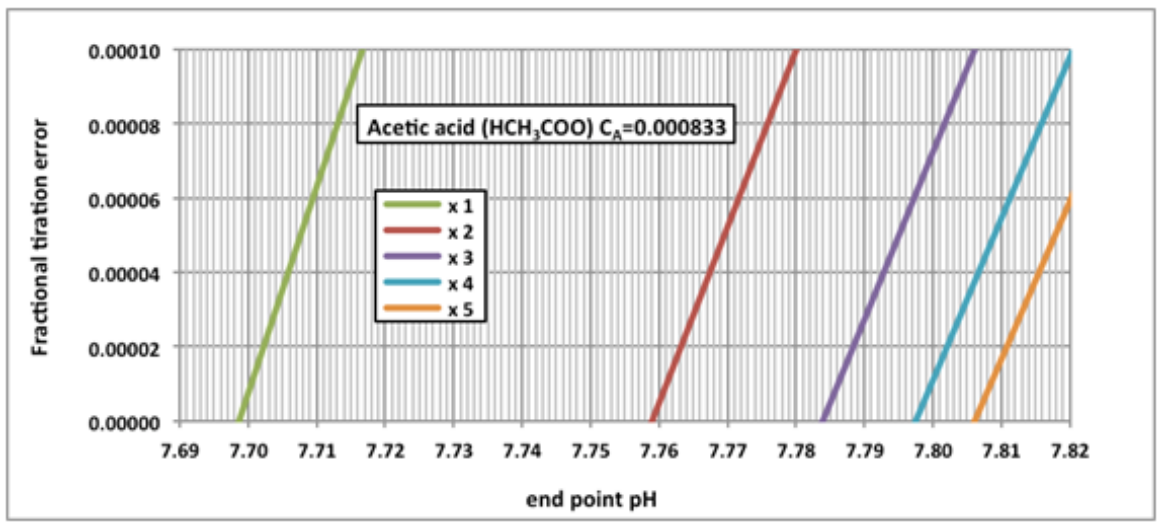

Figure 2. Top left: titration curves of acetic acid with sodium hydroxide at the same concentration; Top right: titrated fraction and Bjerrum index as a function of $\mathrm{pH}$. Middle: fractional titration error. Bottom: enhanced error scale allowing to get the end point $\mathrm{pH}$ value in the titration of $0.000833 \mathrm{M}$ acetic acid with sodium hydroxide $n$ more concentrated times $(n=1,2,3,4$ and 5).

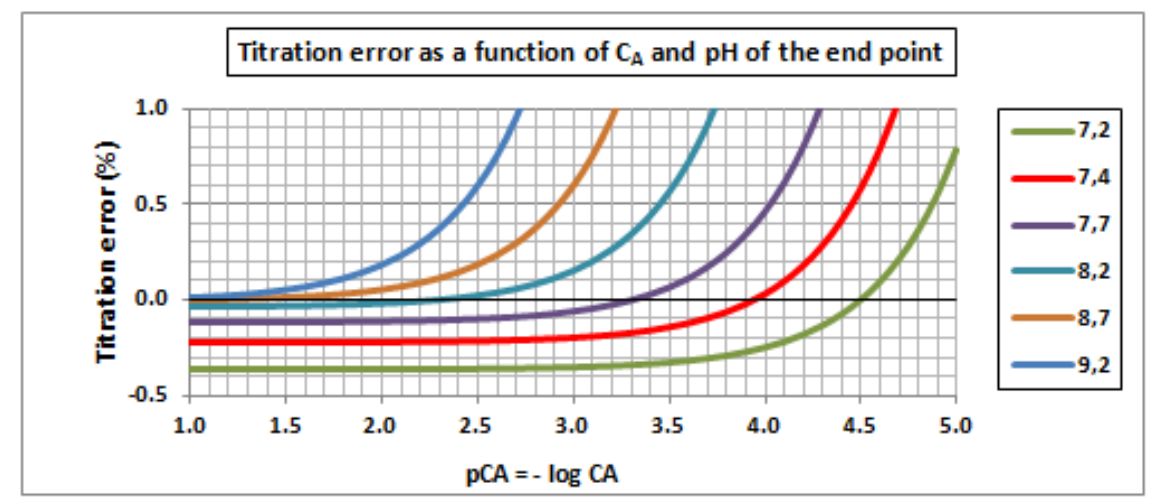

Figure 3. Titration error for acetic acid as a function of $C_{A}$ and $p H$ of the end point.

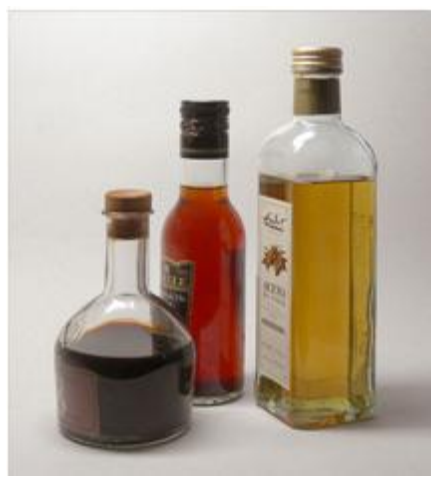

Figure 4. Bottles of vinegar of different formats (wikipedia, n.d.).

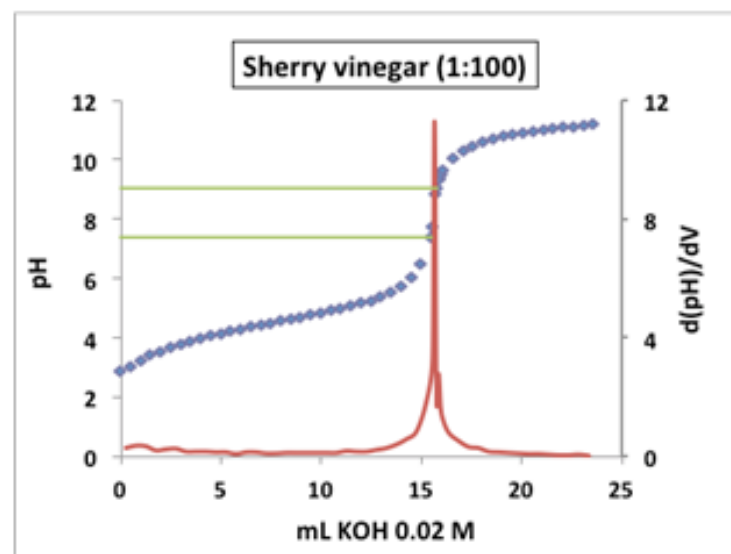

Figure 5. Titration curve of diluted Sherry vinegar 1:100 $\left(V_{0}=25 \mathrm{~mL}\right.$; end point $\left.=15.65 \mathrm{~mL}\right)$. 


\section{PHOSPHORIC ACID SYSTEM AND ITS DETERMINATION IN COLA DRINKS}

Phosphoric acid is a triprotic acid with $\mathrm{pK}_{\mathrm{a} 1}=2.15, \mathrm{pK}_{\mathrm{a} 2}=7.20$ and $\mathrm{pK}_{\mathrm{a} 3}=12.15$, whose titration curve shows (Fig. 6, top) two jumps. The fraction titrated together with the degree of deprotonation are shown in Fig. 6 middle, whereas the curves corresponding to the fractional error for the equivalence points corresponding to both jumps (end point (e.p.) $1^{\circ}$ and e.p. $2^{\circ}$ ) are depicted in Fig. 6 bottom.

The experimental data obtained in the titration of $25 \mathrm{~mL}$ of a $0.04389 \mathrm{M}$ phosphoric acid solution with $0.09948 \mathrm{M} \mathrm{NaOH}$ [16], using a Orion Model $420 \mathrm{~A} \mathrm{pH}$ meter(equipped with an Orion electrode Model 91-57 "Triode" immersed in $4 \mathrm{MKCl}$ saturated with $\mathrm{AgCl}$ prior to use), are shown in Table 4together with the incremental curve ( $\mathrm{pH}$-meter is calibrated with $\mathrm{pH} 4.00,7.00$ and 9.00 buffers).

The theoretical volume required to reach the first and second equivalence points is equal to 11.03 and $22.06 \mathrm{~mL}$, respectively. Since the derivative curve (Fig. 7) shows maximums at 10.90 and $22.15 \mathrm{~mL}$, the titration error will be given by
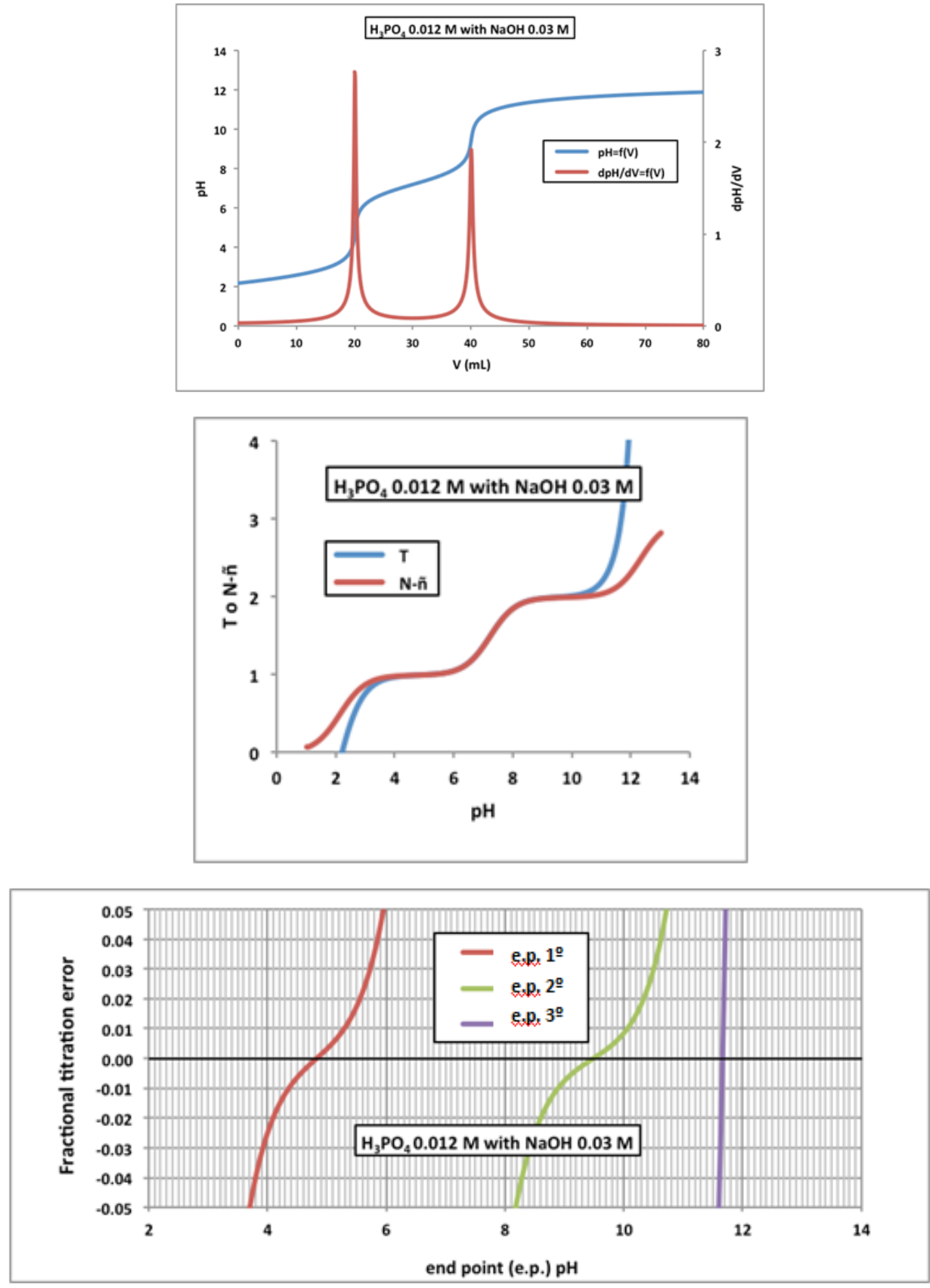

Figure 6. Top: Titration curve of phosphoric acid with sodium hydroxide. Middle: Titrated fraction $(T)$ and degree of deprotonation $(n-\tilde{n})$ as a function of $p H$. Bottom: Titration error at the different end points $($ e.p. $)\left(1^{o} y\right.$ $2^{\circ}$; and $3^{\circ}$ no detectable). 
Titration Error in Polyprotic Acid-Base Titrations: Applications to Titration of Vinegar, Cola Drinks and Antibiotic Batches

$\Delta T_{p f 1}=\frac{V_{p f 1}}{V_{e q 1}}-1=\frac{10.9}{11.3}-1=-0.0118 \approx-1.2 \%$
$\Delta T_{e . p .2}=\frac{V_{e . p .1}}{2 V_{e q 1}}-1=\frac{22.15}{2 \cdot 11.03}-1=-0.004 \approx 0.4 \%$

The titration curves in the concentration range of $1.210^{-1}$ to $610^{-4} \mathrm{M}$ are shown in Fig. 8 (top). In the intermediate range $\left(\mathrm{H}_{2} \mathrm{PO}_{4}^{-} / \mathrm{HPO}_{4}{ }^{2-}\right)$, the $\mathrm{pH}$ is independent of the concentration. The titration error, $\mathrm{T}$, at $\mathrm{pH}$ values close to the end points is also shown in Fig. 8 (middle and bottom). For the determination of $\mathrm{H}_{3} \mathrm{PO}_{4}$ in decarbonated (degassed) cola drinks $[17,18]$ potentiometric titration has to be applied, given its intense colour. The undiluted drink $\mathrm{pH}$ is 2.5 with

$$
K_{a 1}=\frac{\left[H^{+}\right]^{2}}{C_{A}-\left[H^{+}\right]} \rightarrow C_{A}=\frac{\left[H^{+}\right]^{2}}{K_{a 1}}+\left[H^{+}\right]=\frac{\left(10^{-2.48}\right)^{2}}{10^{-2.15}}+10^{-2.48} \approx 4.8 \cdot 10^{-3} M
$$

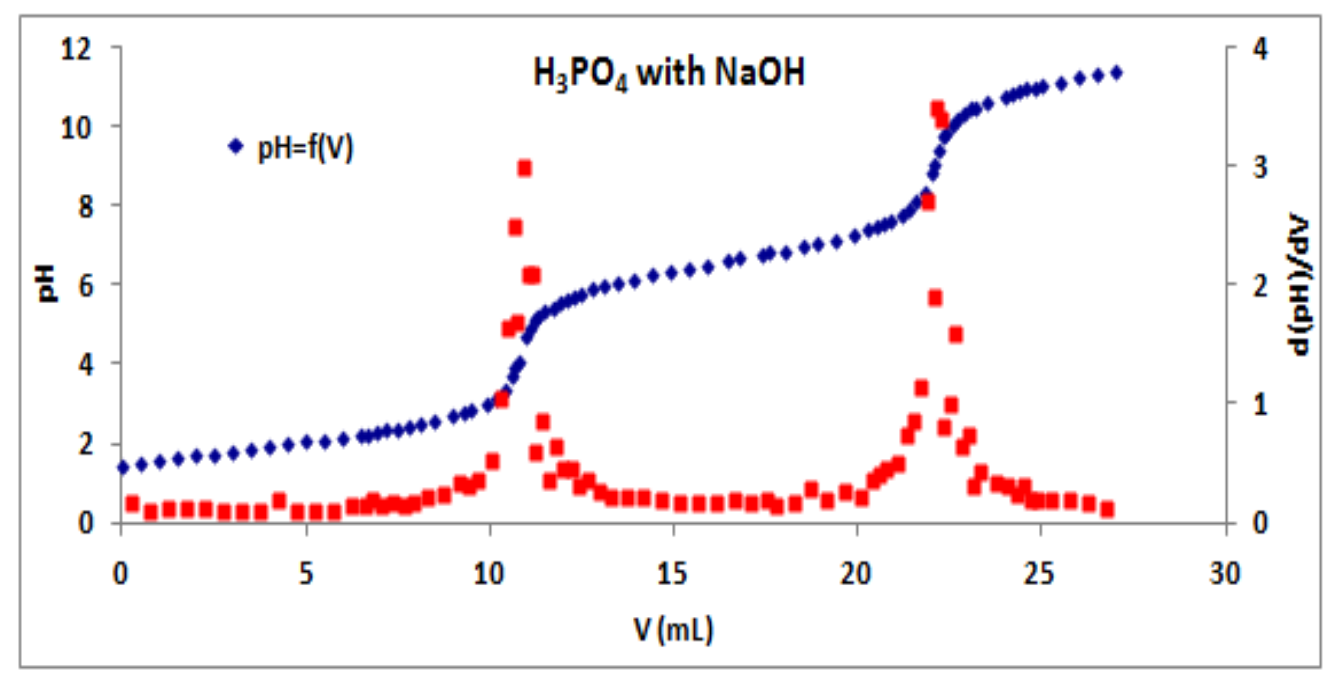

Figure 7. Titration curve and derivative curve corresponding to the titration of $25 \mathrm{~mL}$ of $0.04389 \mathrm{M}$ of phosphoric acid with $\mathrm{NaOH} 0.09948 \mathrm{M}$ (without ionic strength adjustment).

Table 4. Titration of $25 \mathrm{mLof} \mathrm{H}_{3} \mathrm{PO}_{4} 0.04389 \mathrm{M}$ with $\mathrm{NaOH} 0.09948 \mathrm{M}\left(\mathrm{V}_{\text {eql }}=11.03 \mathrm{~mL} ; \mathrm{V}_{\text {eq } 2}=22.06 \mathrm{~mL}\right)$.

\begin{tabular}{|c|c|c|c|c|c|c|c|c|c|c|c|}
\hline $\mathrm{V}(\mathrm{mL})$ & $\mathrm{pH}$ & $\mathrm{V}(\mathrm{mL})$ & $\mathrm{pH}$ & $\mathrm{V}(\mathrm{mL})$ & $\mathrm{pH}$ & $\mathrm{V}(\mathrm{mL})$ & $\mathrm{pH}$ & $\mathrm{V}(\mathrm{mL})$ & $\mathrm{pH}$ & $\mathrm{V}(\mathrm{mL})$ & $\mathrm{pH}$ \\
\hline 0.0 & 1.44 & 6.9 & 2.29 & 11.0 & 4.70 & 14.9 & 6.36 & 20.9 & 7.63 & 23.5 & 10.63 \\
\hline 0.5 & 1.52 & 7.2 & 2.33 & 11.1 & 4.91 & 15.4 & 6.44 & 21.2 & 7.78 & 24.0 & 10.80 \\
\hline 1.0 & 1.57 & 7.5 & 2.38 & 11.2 & 5.12 & 15.9 & 6.52 & 21.4 & 7.93 & 24.2 & 10.86 \\
\hline 1.5 & 1.63 & 7.8 & 2.42 & 11.3 & 5.18 & 16.5 & 6.61 & 21.6 & 8.10 & 24.4 & 10.91 \\
\hline 2.0 & 1.69 & 8.1 & 2.47 & 11.5 & 5.35 & 16.8 & 6.68 & 21.8 & 8.33 & 24.6 & 10.97 \\
\hline 2.5 & 1.75 & 8.5 & 2.56 & 11.7 & 5.42 & 17.4 & 6.78 & 22.0 & 8.87 & 24.8 & 11.01 \\
\hline 3.0 & 1.80 & 9.0 & 2.68 & 11.9 & 5.55 & 17.6 & 6.82 & 22.1 & 9.06 & 25.0 & 11.05 \\
\hline 3.5 & 1.85 & 9.3 & 2.78 & 12.1 & 5.64 & 18.0 & 6.88 & 22.2 & 9.41 & 25.5 & 11.15 \\
\hline 4.0 & 1.90 & 9.5 & 2.84 & 12.3 & 5.73 & 18.5 & 6.96 & 22.3 & 9.75 & 26.0 & 11.24 \\
\hline 4.5 & 2.00 & 9.9 & 2.98 & 12.5 & 5.79 & 18.9 & 7.07 & 22.4 & 9.83 & 26.5 & 11.32 \\
\hline 5.0 & 2.05 & 10.2 & 3.14 & 12.8 & 5.90 & 19.4 & 7.17 & 22.6 & 10.03 & 27.0 & 11.38 \\
\hline 5.5 & 2.10 & 10.4 & 3.35 & 13.1 & 5.98 & 19.9 & 7.30 & 22.7 & 10.19 & & \\
\hline 6.0 & 2.15 & 10.6 & 3.68 & 13.5 & 6.07 & 20.3 & 7.39 & 22.9 & 10.32 & & \\
\hline 6.5 & 2.22 & 10.7 & 3.93 & 13.9 & 6.16 & 20.5 & 7.46 & 23.1 & 10.47 & & \\
\hline 6.7 & 2.25 & 10.8 & 4.10 & 14.4 & 6.27 & 20.7 & 7.54 & 23.2 & 10.50 & & \\
\hline
\end{tabular}


Titration Error in Polyprotic Acid-Base Titrations: Applications to Titration of Vinegar, Cola Drinks and Antibiotic Batches
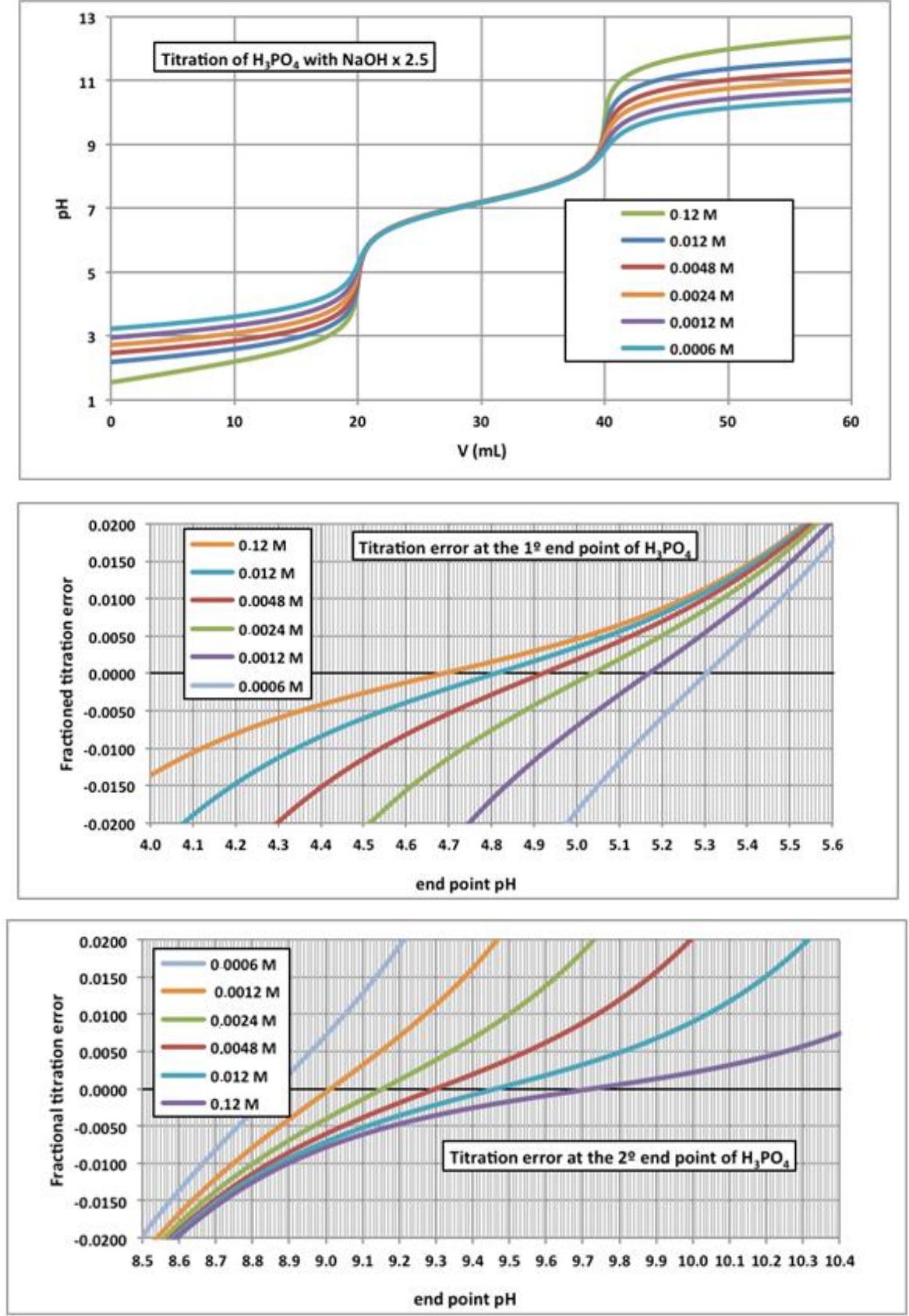

Figure 8. Top: Titration curves of phosphoric acid with sodium hydroxide concentrations 2.5 times more concentrated. Middle: Titration error at varying concentrations of acid for the $1^{o}$ end point. Bottom: Titration error at varying concentrations of acid for the $2^{\circ}$ end point.
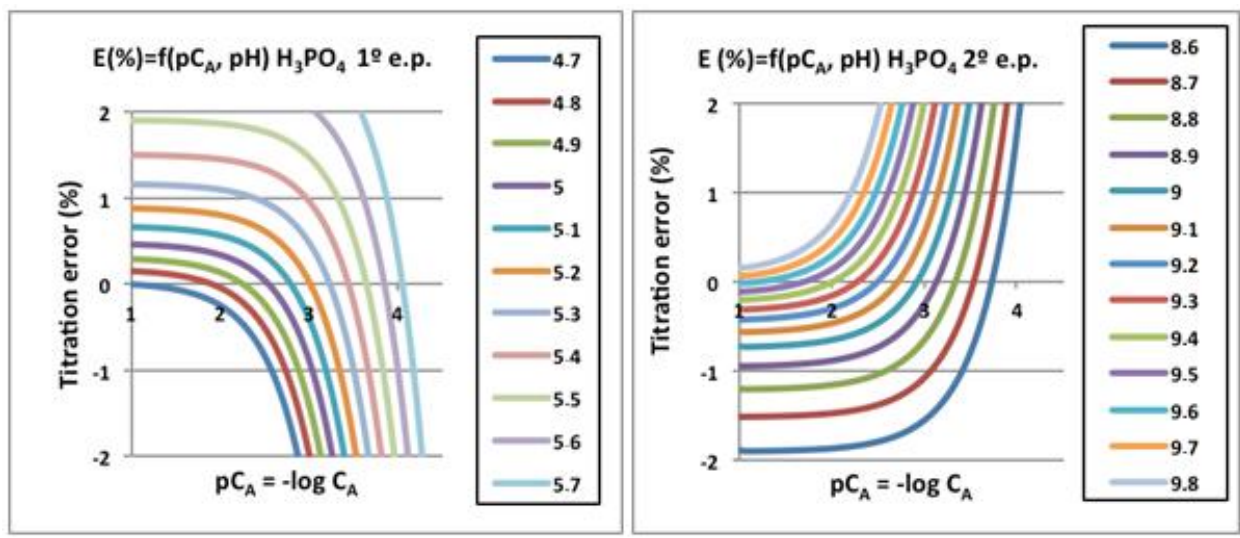

Figure 9. Titration error as a function of concentration of $\mathrm{H}_{3} \mathrm{PO}_{4}$ and $\mathrm{pH}$ of the end point 


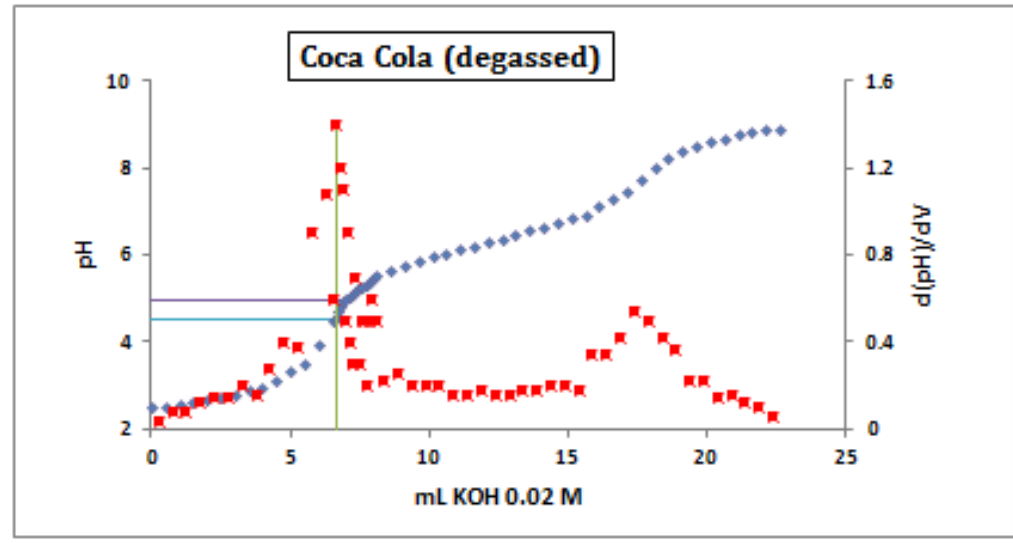

Figure 10. Titration curve of $25 \mathrm{~mL}$ of degassed Coca Cola ( $1^{\circ}$ end point at $\left.6.65 \mathrm{~mL}\right)$

Other acids present (citric acid) exert a negligible influence [17], if titration is carried out to the first end point, since $\mathrm{V}_{\text {eq2 }}>2 \mathrm{~V}_{\text {eq1 }}$. In order to evaluate for routine purposes up to a fixed $\mathrm{pH}$ range, we study how the titration error varies as a function of the concentration at given values of $\mathrm{pH}$ (Fig. 9). It is noted that a $\mathrm{pH}$ value of 5.2 covers the range of $\mathrm{pC}_{\mathrm{A}}$ values from 2.0 to 3.3 with an error lower than $1 \%$. Likewise, a $\mathrm{pH}$ value of $8.8-9.0$ ( $2^{\text {nd }}$ end point) also covers that same range of $\mathrm{pC}_{\mathrm{A}}$.

The degassed (using an ultrasound bath) Coca Cola titration curve(Figure 10) shows that the error is minimal at the $1^{\circ}$ end point when the $\mathrm{pH}$ is between 4.5 and 5.0, values some lower than expected, being logical the difference taking into account the complexity of the medium. The phosphoric acid concentration is $\approx 5.3210^{-3} \mathrm{M}$.

\section{TITRATION CURVES OF CIPROFLOXACIN AND VANCOMYCIN}

Antibiotics are important antimicrobial agents whose behaviour in vivo is significantly influenced by their physicochemical properties, such as degree the of ionization and the ability to chelate metal ions. The transport of the active principle through the cells and the biological membranes is a function of their physical and chemical properties and $\mathrm{pK}_{\mathrm{a}}$ values, which play a vital role in the development of new drugs. The acid-base character [19] is a key factor in the behaviour at the molecular level, since it governs solubility, absorption, distribution, metabolism and elimination. Antibiotics, belonging to various therapeutic families, i.e., macrolides, penicillins, sulphonamides, tetracyclines, cephalosporins, glycopeptides, carbapenem, are polyprotic acids or bases. The ciprofloxacin hydrochloride $\left(\mathrm{pK}_{\mathrm{a} 1}=3.01 ; \mathrm{pK}_{\mathrm{a} 2}=6.14 ; \mathrm{pK}_{\mathrm{a} 3}=8.70 ; \mathrm{pK}_{\mathrm{a} 4}=10.58\right)$ and the vancomycinglycopeptide $\left(\mathrm{pK}_{\mathrm{a} 1}=2.18\right.$; $\left.\mathrm{pK}_{\mathrm{a} 2}=7.75 ; \mathrm{pK}_{\mathrm{a} 3}=8.89 ; \mathrm{pK}_{\mathrm{a} 4}=9.59 ; \mathrm{pK}_{\mathrm{a} 5}=10.40 ; \mathrm{pK}_{\mathrm{a} 6}=12\right)$ titration curves are shown in Fig. 11 left and right, respectively.

It is possible to use visual indicators in the case of vancomycinglycopeptide, as shown in Table 5, after applying the formalism described in the first application. Of the indicators tabulated the one that is better is the red of methyl, although the ideal would be to have one that turns between $\mathrm{pH} 4.4$ and 5.8. The case of ciprofloxacin requires further study in the direction applied to the case of phosphoric acid, since in practice the derived titration curves obtained from the experimental data are far from the ideal behaviour shown in Fig. 11 left.
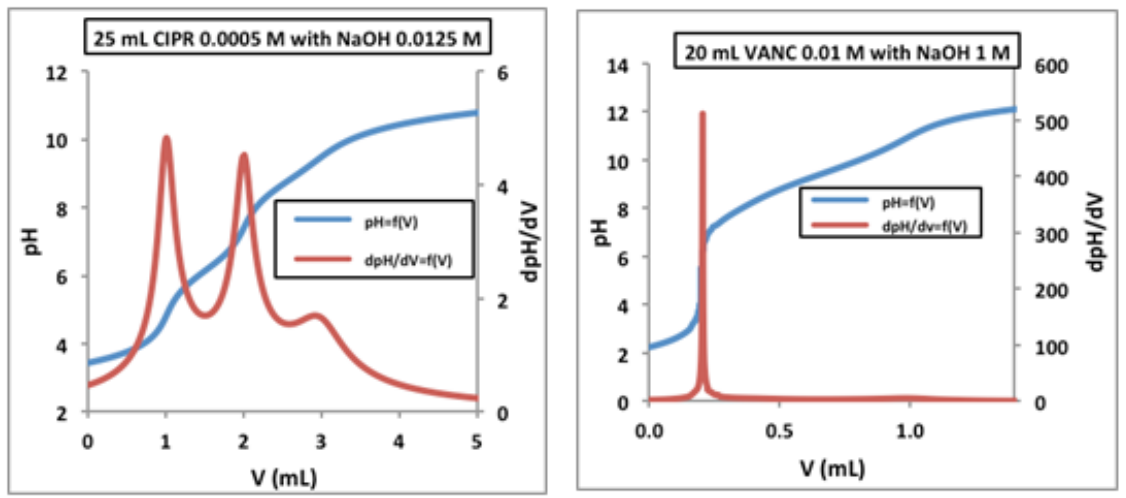

Figure 11. Titration curves of ciprofloxacin (left) and vancomycin (right). 
Titration Error in Polyprotic Acid-Base Titrations: Applications to Titration of Vinegar, Cola Drinks and Antibiotic Batches

Table 5. Estimation of titration error corresponding to $0.01 \mathrm{M}$ vancomycin.

\begin{tabular}{|l|c|c|c|}
\hline Indicator & pH Range & Color change & $\%$ Error \\
\hline Ethyl Orange & $3.4-4.8$ & Red to Yellow & $-9.7 \%--0.3 \%$ \\
\hline Bromocresol Green & $3.8-5.4$ & Yellow to Blue & $-3.9 \%-0.03 \%$ \\
\hline HIn & $4.4-5.8$ & & $-1.0 \%-1.1 \%$ \\
\hline Methyl Red & $4.8-6.0$ & Red to Yellow & $-0.3 \%-1.7 \%$ \\
\hline Chlorophenol Red & $4.8-6.4$ & Yellow to Red & $-0.3 \%-4.3 \%$ \\
\hline
\end{tabular}

\section{CONClusions}

The traditional mathematical description of the titration curves described in terms of isolated points, fails for complex systems, such as polyprotic acid or bases and their salts. Nevertheless, from the charge and mass balances, the volume of titrant added (the extensive property) may be written as a explicit function of the $\mathrm{pH}$ (the intensive property); i.e., the titrant volume is calculated as a function of $\mathrm{pH} ; \mathrm{V}=\mathrm{f}(\mathrm{pH})$.

Using the dissociation and formation ( $\tilde{\mathrm{n}})$ functions incorporated in the equations defining the charge and mass balances expressions considerably reduces the chemical complexity involvedfor tracing a titration curve or evaluate the titration error. The equations derived can be incorporated into a spreadsheet to calculate as a function of $\mathrm{pH}$, the degree of protolysis of each acid species, the formation function, the titration curve (the titration fraction) and the titration error, $\Delta \mathrm{T}=(1 / \mathrm{n})[(\mathrm{T}-\mathrm{n}) / \mathrm{n}](\mathrm{n}=0,1, \ldots, \mathrm{N})$, for the $\mathrm{H}_{\mathrm{N}} \mathrm{A}$ case). Note that the approximation $\mathrm{T}=\mathrm{N}-\tilde{\mathrm{n}}$ (where $\mathrm{T}$ is the titration fraction and $\tilde{\mathrm{n}}$ the formation function), applies except at very high or low $\mathrm{pH}$ values, i.e., the dissociation curve is the mirror image of the formation curve. Ionic strength is assumed to be constant through the titration. This condition is normally fulfilled by addition of a neutral salt in a sufficient amount.

Given the acidity constants, the error associated with indicator $\mathrm{pH}$ ranges may be easily estimated. As the indicator $\mathrm{pH}$ ranges are tabulated in monographs and textbooks, only the corresponding titration volume has to be calculated from the inverse titration $\mathrm{V}=\mathrm{f}(\mathrm{pH})$ curve. The titration error resulting from a preset final $\mathrm{pH}$ value may be immediately obtained in a similar way.

This paper provides first examples of optimizing a priori. On the basis of the relevant curves $\mathrm{V}=\mathrm{f}(\mathrm{pH})$ or $\mathrm{T}=\mathrm{f}(\mathrm{pH})$ one may select the appropriate $\mathrm{T}=\mathrm{T}_{\text {eq }}$ values where abrupt changes in the $\mathrm{pH}$ occur. This allows a better understanding of chemical reactions under given or required conditions as illustrated with the case of the acetic acid and phosphoric acid systems. Applications of the paper include the determination of acetic acid in vinegar, the determination of phosphoric acid in cola drinks, and the evaluation of purity in vancomycin batches.

\section{REFERENCES}

[1] Oliveira A. F., de Souza Silva A.F.,Tenan M.A. and Olivo S.L., TIT:GERunaplanilhaelectrónicaparasim ulacro de titulação de mistura de compostospoliproticos, Quim. Nova 30(1), 224-228 (2007).

[2] Ullmann G.M., Relations between protonation constants and titration curves in polyprotic acids: A Critical View, J. Phys. Chem. B107 (5), 1263-1271 (2003).

[3] Dougherty D.P., Neta E. R. D.C., Mc Feeters R.F.,Lubkin S.R. and Breidt F., Semi-mechanistic partial buffer approach to modeling $\mathrm{pH}$, the buffer properties, and the distribution of ionic species in complex solutions, J. Agric. Food Chem. 54 (16), 6021-6029 (2006).

[4] Lang W. and Meier N., Calculation of the $\mathrm{pH}$ and the titratable acidity in clinically used infusion solutions,Comput. Methods Programs Biomed. 87 (2), 160-169 (2007).

[5] Gonçalves E. M. and Conceição A.C.L.,Constantes de acidez de ácidosdipróticos a partir de titulaçõespoten ciométricas: Ilustração dos princípios do cálculoatravés da construção de um algoritmomuito simples, Quim. Nova 34 (6), 1074-1078 (2011).

[6] Cañamares Marin G., Error de valoración en valoraciones de ácidospolypróticos, Trabajo de Fin de Grado, Departamento de QuímicaAnalítica, Universidad de Sevilla, (2015).

[7] Ventura D.A. and Ando H.Y., General method for calculation of hydrogen-ion concentration in multicomponent acid-base mixtures, J. Pharm. Sci. 69, 891-896 (1980).

[8] Frison G. and Calatroni A.,On the existence and uniqueness of the equilibrium of arbitrary Brønsted acidbase mixtures, Chem. Educator 11 (3), 150-161 (2006). 
[9] Asuero A.G. and Michalowski T., Comprehensive formulation of titration curves for complex acid-base systems and its analytical Implications, Crit. Rev. Anal. Chem. 41 (2), 151-187 (2011).

[10] De Levie R., Advanced Excel for Scientific Data Analysis, 3th. Ed., Atlantic Academic: New York (2012).

[11] Asuero A. G., Jiménez-Trillo J.L. and Navas M.J., Mathematical treatment of absorbance versus pH graphs of polybasic acids, Talanta 33, 929-934 (1986).

[12] Butcher J. and Fernando Q., Theoretical error in acid-base titrations, J. Chem. Educ. 43 (10), 546-550 (1966).

[13] Kraft A., The determination of the pKa of multiprotic, weak acids by analyzing potentiometric acid-base titration data with difference plots, J. Chem. Educ. 80 (5), 554-559 (2003).

[14] Harris D.C., Quantitative Chemical Analysis, $8^{\text {th }}$ ed., W.H. Freeman and Company: New York (2010).

[15] Bishop E., Indicators, Pergamon Press, Oxford (1972).

[16] Burnett J. and Burns W.A., Using a spreadsheet to fit experimental pH titration data to a theoretical expression: estimation of analytite concentration and Ka, J. Chem. Educ. 83 (8), 1190-1193 (2006).

[17] Murphy J., Determination of phosphoric acid in cola beverages. A colorimetric and $\mathrm{pH}$ titration experiment for general chemistry, J. Chem. Educ. 60 (5), 420-421 (1983).

[18] Bello M.A. and González A.G., Determination of phosphate in cola beverages using nonsupressed ion chromatography. An experiment introducing ion chromatography for quantitative analysis, J. Chem. Educ. 73 (12), 1174-1175 (1996).

[19] Avdeef A., Absorption and Drug Development: Solubility, Permeability, and Charge State, Wiley: New York (2012).

Citation: A. Asuero, "Titration Error in Polyprotic Acid-Base Titrations: Applications to Titration of Vinegar, Cola Drinks and Antibiotic Batches", International Journal of Advanced Research in Chemical Science (IJARCS), vol. 4, no. 9, pp. 7-20, 2017. http://dx.doi.org/10.20431/2349-0403.0409002

Copyright: (C) 2017 Authors. This is an open-access article distributed under the terms of the Creative Commons Attribution License, which permits unrestricted use, distribution, and reproduction in any medium, provided the original author and source are credited. 